patient, and after certain operations for squint it may be of advantage to be able to vary the relative position of the apertures for different patients.

In this new type there are two discs back to back which can be rotated independently of each other. Each disc is perforated by a curved slit, the aperture being produced by the overlapping of the slits. By a suitable manoeuvre, it is possible to place the aperture in any position on the disc save in the exact centre, an

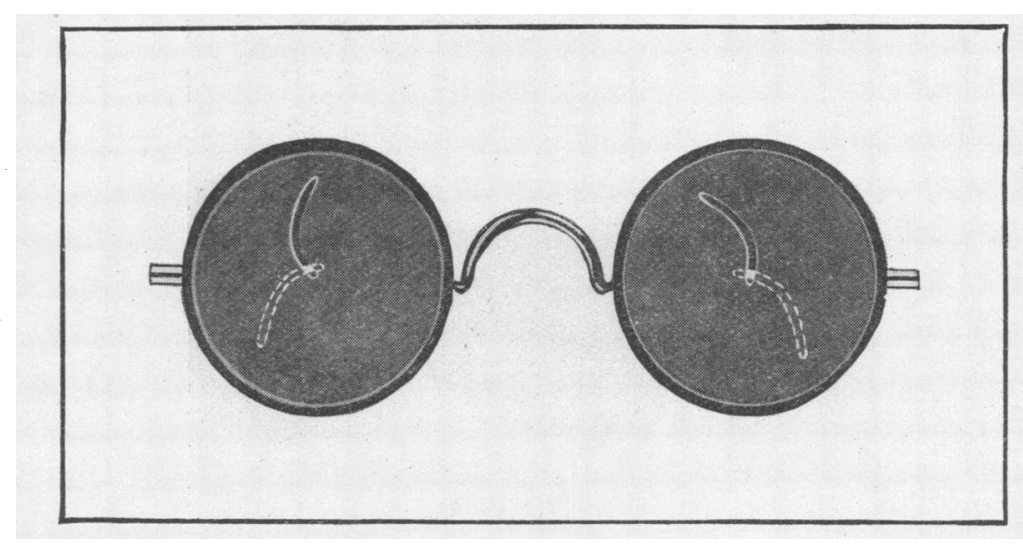

apparent disadvantage which can be overcome by de-centring an equal amount in each disc. Thus a vertical as well as a horizontal correction may be made. It is also possible, of course, to obliterate the aperture should only one be required.

The slits are at present made $2 \mathrm{~mm}$. in width. Rotation is facilitated by lightly smearing the opposing surfaces of the discs with vaseline; they are sufficiently firmly gripped by the rims to prevent accidental movement.

The spectacles have been made by, and are obtainable from, Messrs. Clement Clarke of Wigmore Street.

\title{
ANNOTATION
}

\section{Blindness in Great Britain}

Some interesting figures were supplied by the Minister of Health in moving, in the House of Commons, the second reading of the Blind Persons Bill on November 11, 1937. He stated that the total number of blind persons registered in England, Scotland and Wales was about 78,000 . Of these approximately 57,000 were aged 
50 years or more, and there were 8,000 persons between the ages of 40 and 50 years. The increase in the total number of the blind was not, in his opinion, due to any real increase in numbers, but to more complete registration, longer life, and increased inducements to blind people to register at the present time. The total number of blind children between the ages of 5 and 16 years had fallen since the year 1925 from 3,104 to 1,916 . Only $2 \cdot 95$ per cent. of the 8,700 new cases which were registered in the year ending March 31, 1937, were under the age of 16 years, and about 89 per cent. were over the age of 40 years.

As is well known, the first clause of this Bill provides for a reduction of the age for the receipt of old age pensions in the case of blind persons from 50 to 40 years of age.

No one will grudge the blind the amelioration of their lot which is fore-shadowed in this Bill, if, as we all hope, it passes on to the Statute Book.

The age of 40 years was chosen because of the difficulty of teaching a trade after that age. A lower limit would diminish the incentive of blind persons to attempt to earn their daily bread.

The only regrets that we can see will be those of the blind who have gone before. We fancy we see "Poluphloisboisterous" Homer congratulating the first of the new beneficiaries under the Act who is conveyed across the Styx and commenting on how times are changed. He never received 10 drachmae a week.

\section{ABSTRACTS}

\section{I.-OPTIC NERVE}

(1) Behr, Carl (Hamburg).-New anatomical facts on papilloedema. (Neue anatomische Befunde bei Staungspapille). Arch.f. Ophthal., Vol. CXXXVII, p. 1.

(1) In this contribution to the pathogenesis of papilloedema of intracranial origin Behr demonstrates in anatomical preparations, embedded in gelatine so as to avoid shrinkage and the formation of artefacts, the presence of spaces or small cavities between the nerve fibre bundles along the whole length of the optic nerve from the disc to the optic canal: the nerve fibres separated from each other or pressed together in such a way as to indicate that these spaces must have been caused by a collection of fluid under pressure between the nerve fibres intra vitam. He lays emphasis on the fact that this oedema is intrafascicular, and is not present in or under the pial sheath, septa or in the axial connective tissue strand; 